\title{
Occupational safety and health: the union perspective
}

\author{
Ross Wilson*
}

\section{Introduction}

The basic principle I wish to emphasise today is that, in the absence of any reasonable, effective alternative mechanisms capable of shifting the costs of accidents onto employers, or of compelling them to implement adequate safety precautions, there exists a key role for the Government and the law to play in preventing occupational injury and disease.

I shall examine the basic principles underlying the approach ACOSH has taken to reform, and the strong case which exists for Government intervention to protect workers from death and injury. I shall also examine some alternative strategies for control in this area and finish by briefly outlining what a new Work Environment Act should contain as the basis for a more effective tripartite approach to the prevention of death, injury and disease caused by hazards in the work environment.

\section{The basic principles}

The June 1988 ACOSH Discussion Paper on OSH Reform began by identifying the basic principles underlying the preferred reform model which it proposed to Government.

(1) The present toll of injury and disease can be reduced by appropriate preventative measures. These may be applied at all levels, from the workplace to the Government.

A New Zealand worker dies from a work accident about once every two days. Every day 4 workers are permanently disabled and 120 others will be injured to the extent that they will be off work for more than a week. In addition there is the hidden hazard of occupational disease. The health problems caused by new technology and the flood of toxic chemicals into the workplace have yet to be accurately identified. The February 1984 I.L.O. Information Bulletin reported that the number of chemical substances to which workers were exposed had increased from 212,000 to 6 million between 1965 and 1984.

A joint study in the USA by the National Cancer Institute, the National Institute of Environmental Health \& Safety and the National Institute for Occupational Safety \& Health estimated that somewhere between 23 percent - 38 percent of future cancers in the 
United States will be attributable to current or previous workplace exposures to just 6 known carcinogens (Wailer, 1983). Other scientists have disputed these figures but they are still an indication of the risk workers are exposed to.

One thing is certain, and agreed by the employer, union and Governmen representatives at ACOSH - we can do much better. The most recent ILO Statistics (International Labour Office, 1988) confirm this. New Zealand's work fatility rate is about the same as Germany and France; three times worse than the USA; 4 to 5 times worse than Sweden and Japan. One would expect injury rates to reflect similar patterns.

A comprehensive and effective accident and disease prevention policy would undoubtedly reduce the present level of death, injury and disease.

(2) A preventative strategy needs to focus on underlying work systems and not solely on making workers and employers 'aware'. Accidents and diseases do not necessarily occur because of 'apathy' or carelessness but also through unsafe and healthy systems, processes and tools.

The conventional wisdom that accidents are caused by apathetic or (more often) careles workers has long been used as a smoke-screen to draw attention away from the hazardous nature of the work environment. The 1972 Robens Committee support for the "apathy" doctrine has been subject to strong criticism (Nichols and Armstrong, 1973) and on close examination the alleged importance of apathy proves to be greatly over-emphasized.

Even if it were possible to classify most accidents as being caused either by "unsafe acts" (worker-failure) or "unsafe conditions" (e.g. machine failure) research (Ashford, 1976, pp. 114-115) suggests that only one third or less are the result of worker failure (and many of these may be the fault of persons other than the worker). Moreover, the unsafe acts/unsafe conditions dichotomy is itself an over-simplification since almost all accidents are the result of worker-environment interactions to which one cannot attribute a single cause. No doubt unsafe acts by some workers do contribute to some accidents, but there is overwhelming evidence that inexperience, inadequate language comprehension, insufficient training and information, production pressures, fatigue, stress and monotony are among the most common explanations of worker-error, rather than apathy.

Probably the most comprehensive study of the causes of accidents was undertaken at the National Institute of Psychology in the United Kingdom (Powell and Ors, 1971) and after an investigation of 2,000 accidents it concluded that nearly all accidents are the result of unsafe systems of work. The study concluded that the three factors which were of overriding influence on the accidents they investigated were:-

(a) That risks were so much an integral part of work systems as at present arranged, that the more work was done, the more accidents occurred;

(b) That the risks which accompanied each task were specific and could be changed by changing details of the task; and

(c) That people reduced their accident rate by gaining experience, i.e. they learned to avoid risks. But this experience was highly specific and became blurred after time spent on other tasks.

It is clear therefore that any national OSH policy must focus primarily on ensuring a safe work environment and a safe system of work.

(3) For economic and social reasons, a basic level of safety needs to be imposed by the law on all enterprises.

It is unfortunately a fundamental truth that unsafe systems of work are encouraged by economic forces, which favour cheaper commodities over those produced at a higher cost, because making workplaces safer generally carries with it direct or indirect costs. It is also true that optimum conditions for health and safety may sometimes coincide with optimum conditions for profit, but in many of those situations the motivation is often ordinary humanity, the desire for a good public image, or a concern for increased productivity (indirectly related to profit) arising out of good industrial relations. In an increasingly competitive economy more and more employers are likely to cut expenditure on health and safety in order to maximise profits.

The problem in New Zealand is compounded by the number of small firms. Of a total of 24,300 registered factories in the country only 490 employ 100 or more workers and 88 percent of factories employ less than 20 workers (Department of Labour, 1987). Professor Bill Glass (Glass, 1987) listed the features of small workplaces which impose vulnerability on those employed as being:-

* Undercapitilised

* Inferior environmental conditions

* Greater chemical exposure

* Unlabelled and cheaper raw materials

* Higher injury rate

* Higher occupational illness rate

* Inferior inspection

* Inferior occupational health services

* Under-unionised/lower pay rates

* Longer working hours

* Award conditions ignored.

Society demands the achievement of goals other than profit and increasingly a reasonable level of protection of workers' health and safety has been recognised as a worthy goal. The British Common Law has not helped in this regard. The principles on which the Courts have decided the issues derive from the doctrine of master and servant, described by one 18th century jurist as one of the three great relationships of private life, the other two being those of husband and wife and parent and child. Recognising basic rights Parliament has intervened on behalf of the wife and child and there is strong justification for intervention on behalf of workers particularly in respect of their health and safety.

Workers and unions are increasingly saying that they don't want employers and scientists accepting certain levels of risk on their behalf. They want a minimum level of risk enforced for all workplaces and to have a real input into determining those safety standards.

(4) Lax enforcement of the law undermines the position of employers who responsibly abide by these minimum legal standards. The law should therefore be adequately, uniformly and equitably enforced, through a system of inspection and the imposition of penalties for contraventions.

It is one of the lesser known facts of our social history that the motivation of the more philanthropic millowners, such as Robert Owen \& Sir Robert Peel, in promoting the early Factories Acts was as much self-interest as social conscience. One historian (Henriques, 1979) noted that they supported regulations to raise standards in factories to the level of their own "to prevent their rivals undercutting and underselling themselves by exploiting the more defenceless of their workers".

The main problem with the system of statutory safety standards in the past has been that it has not been adequately enforced. The inspectorate has been understaffed and in any event, has shown a reluctance to prosecute. In the rare event of prosecution, courts were 
reluctant to convict, and even where they felt compelled to do so, imposed minimal fines. In short, the system of enforcing legal standards has not failed (as is often alleged) - rather its potential has never been fully exploited.

(5) Because occupational health and safety is an issue affecting employers, workers and the Government, the establishment of a policy and the determination of the basic standards of safety and health secured by law should involve a statutory tripartite process at national level. In addition, it is through these tripartite structures that any conflicts which may arise between employers and unions over health and safety issues can be resolved.

The protection of workers' health and safety is not simply a straightforward issue of law and industrial relations. It necessarily involves quite technical and complex issues and as a consequence the dogma has developed that for any particular hazard there is a correct standard for protection that can only be set by qualified technical experts. In my view the process of standard setting involves two stages:-

1. The technical stage of establishing a link between hazard and its consequent health effects. This is sometimes called risk assessment and is properly the province of technical experts.

2. The stage of evaluation of the social impact of those health effects. This stage is properly the province of laypersons, including the representatives of workers who are exposed to the risks.

This distinction is a fundamental one and has to some extent been recognised in a de facto way in recent years. This distinction underlies the preferred model recommended by ACOSH which provides for decisions on standards, as a social process, to be taken by a Tripartite Commission, rather than a committee of experts.

(6) Although the provision of a safe and healthy workplace is a management responsibility, workers need to be involved collectively in applying and monitoring safe and healthy conditions in the workplace.

It is of fundamental importance to workers that they do have rights to help protect their own interests in health and safety matters. Neither the voluntary efforts of employers nor the creation or enforcement of legislation has yet succeeded in reducing work accidents and disease to acceptable levels.

One criticism of the safety inspectorates, stemming mainly from the Chicago school of lawyer-economists, is that regulatory agencies tend to be captured or co-opted by the industries they are set up to regulate. While this may be a danger it is certainly not inevitable. It is true that, in the past, the inspectorates have been too close to management and have paid too little attention to the views of workers. It is therefore important to put in place effective structures to ensure worker involvement in health an safety issues in the workplace. The Code of Practice for Health and Safety Representatives and Committees developed by ACOSH provides such a structure which, if made mandatory with Representatives having legal rights, can monitor and complement the work of the Inspectorate. Such a system is also an important expression of the principle of industrial democracy. If workers have a right to have a say in anything at all at work it should be the right to have a say in decisions affecting their health and safety. But it is important that this increased worker participation should not be regarded as a substitute for legally prescribed standards and regulations on health and safety hazards. The Health \& Safety Representative system should be seen as complementary to strong legislative regulation; as one of the means available to Representatives for exerting countervailing pressure for health and safety considerations to balance the financial pressure which often works against improvements in health and safety.

That concludes my consideration of the ACOSH Basic Principles. I have spent some time on them because they are the fundamental underpinning to the preferred reform option recommended to, and approved in principle by, the Government.

\section{Mechanisms for hazard control}

I wish now to consider the main mechanisms which might be available for controlling work hazards. I do so from the premise that employers are often not prepared to incur costs or reduce the productivity necessary to improve workplace safety unless they are subjected to some form of external pressure over and beyond normal market forces. There are really 4 such mechanisms - actions for damages at Common Law, an injury tax, variable Accident Compensation levies, and regulation by statutory standards.

The Common Law still imposes a duty on employers to provide a safe work environment. Since 1974, however, there has been no sanction for breach of that duty because the Accident Compensation Act abolished the right to sue for damages for personal injury by accident. All claims for personal injury, irrespective of fault, are of course made to the ACC.

Just how effective that Common Law sanction was as an accident prevention mechanism will always be debated. It is strongly argued by some that the potentia financial incentive to avoid accidents was almost invariably negated by insurance and that in any event, the cost of damages claims was generally small when compared with employers' costs. The real problem with the tort action is that it was inefficie unsatisfactory in achieving its primary purpose - the provision of compensaion to accident victims - so it has been replaced in New Zealand and there is no real public wish resurrect it.

An alternative, and untried, technique for hazard control is the injury tax which has been promoted by some economists. The idea is that firms could choose to accept higher injury and disease rates and pay their associated costs, including the injury tax, or they could invest in preventative measures in order to reduce their incidence. In my view the injury tax can readily be rejected. It is no more acceptable than waiting for another thalidomide disaster and then taxing the responsible company for every limbless child born. In addition, occupational diseases may have a latency period of 20 years or more and a lot can happen to a company in 20 years which will enable the tax liability to be avoided.

The third mechanism I wish to consider are variable Accident Compensation levies. The theory is that if ACC levies are adjusted to reflect each employer's previous accident record (so that employers with bad records have to pay high levies and those with good records pay low levies or receive rebates) then each employer will be given a financial incentive to reduce workplace hazards. Our Accident Compensation Scheme already has levy classification system of 104 industrial classes and employers pay levies roughly proportionate to the costs imposed by the levy on the fund. This has not in itself acted as a financial incentive on employers to invest in accident prevention and thereby reduce heir evies. In fact instead of cleaning up their own act employers invariably blame the for increases in their own accident costs. The Freezing Industry employers have been particularly outspoken and have never acknowledged that they can substantially influence their own levies by reducing the number and severity of accidents in their industry.

A further extension of the levy classification system is what is known as experience or penalty-rating. Both relate levies to the individual employer's accident record and arguably provide the necessary financial incentive to improve safety performance. There are sobly even partially applied to firms with less than about 100 employees; secondly the system 
cannot take into account occupational diseases which frequently have time-lags of 20 years before symptoms appear; and thirdly if experience-rating is intended to "internalize" the full full costs of accidents this the full costs of accidents. Nevertheles compensation despite these difficulties it is possible to develop a system which will at least achieve greater equity as between different employers within the same levy class than the present system can do.

Penalty-rating provides the best option if accident prevention is the primary objective. This involves the imposition of an additional penalty levy on an employer with a bad This involve indicate a greater than average claims record or we we the Ontario risk. Penally-rating the basis of claims Workers Compensation Scheme. The philosophy there is that employers cannot be induced to do much about safety under a system of rewards and punishments, unless the punishments are sufficiently heavy to make an impact. In this respect, penalty-rating has a strong advantage over experience-rating, unless the latter is so structured that the ful costs of accidents are reflected in the penalty levy.

Penalty-rating on the basis of observed conditions is a system which has worked well Penalty-rating on in British Columbia. There the standard setting and into the Compensation Board and the inspectorate is able to use claims data as the basis for inspections and the imposition of penalty levies where hazardous workplace conditions are observed.

I would suggest therefore that there is probably some value, in accident prevention In terms, in the intod the Accident and penalty-rating. It would be necessary for this to be done theng Compensation Corporation and is a cogent argument for the proposed new OSH Agency to be closely linked with the ACC.

However, there are real problems in any strategy relying solely on economic incentives to encourage safety. Firstly, firms do not necessarily act in the economically rational way assumed in economist's models. Secondly, it is probably impossible to apply such a assumed in to to easy to disguise the strategy to reducing the in costs of such health hazards and with long latency
diseases is likely to be very limited.

This leaves Government intervention by means of statutory standards. I suggest that this is the most appropriate and potentially most effective mechanism for several reasons. Firstly mandatory safety standards are necessary to "internalize" the costs of work-related Firsty mand the measures necessary to reduce injury and disease, the know enough or in work hazads to a socially accpicty for the many industries are not sufficiently strong collectively to bargain effectively for the necessary health and safety protection. In any event the provision of a work environment
up to a socially acceptable level of safety should not be a bargaining matter.

Where persuasion and education fail, where firms are unwilling to improve their safety performances voluntarily, where economic incentives prove ineffective or inappropriate perfow is the only technique capable of exerting pressure and compelling firms to observe the safe working practices, and of punishing offences. Its ectiven demonstrated, but published studies are also available. When the British Power Press Regulations superseded a former voluntary code of practice in 1965 the number of powe press accidents in the U.K. dropped dramatically from 503 in 1964 to 153 in 1972. A similar study (Lewis-Beck and Alford, 1980) was undertaken in the USA which similar stude coal-mining industry directly correlated with the Federal Government's budget allocation to coal-mine industry directly correlated

health and safety regulation. As I mentioned earlier the system of enforcing legal standards has not failed in this country - rather its full potential has never been realised. The success or failure of this application of sanctions, and the enforcement and administration of the legislation. I want to now look at each of these briefly.

There is a need to review on an ongoing basis the type and level of standards to ensure that they take account of rapid technological change and equally rapid structural changes in the labour force. By minimum standards I do not mean minimal. "Safe" for an occupational hygienist appears to mean safe in the sense of an acceptable level of risk. "Safe" for the worker almost universally means no risk at all.

The reality is that the minimum regulated standards will usually be a compromise between the interests of capital and labour in our society. To ensure that the balance is fair the legislation should clearly spell out the paramountcy of worker safety and should provide for worker input in standard setting through the tripartite commission.

The type of standard used is also an issue. A performance standard defines the employer's duty by reference to the outcome to be achieved; a specification standard defines the duty in specific terms (e.g. approved safety frames on tractors). Performance standards are said to be more flexible and adaptable but they can also be vague and difficult to enforce. Specification standards provide a clearer guide and are readily enforceable an should be preferred where possible for this reason. Any new legislative policy should provide for the use of each type of standard selectively depending upon the type and potential severity of the hazard.

The sanctions provided for in the legislation must be also effective. There is a need for a multi-faceted approach and provision should be made for:

\section{Fines}

They must be sufficiently high to be a deterrent; to ensure that employers have more to lose by infringing the regulations than complying with them. To overcome the apparent reluctance of courts to convict and penalize representatives of their own social class the present criminal penalty system could be replaced with a more flexible system of civil penalties, imposed by the inspectorate and recoverable in the Courts on civil standards of proof. Such a system operates effectively in the USA and Canada.

\section{Preventative orders}

These orders enable the inspectorate to compel the taking or cessation of offensive activity. They operate very effectively in other countries and are already provided for in the Factories and Commercial Premises Act. Their effectiveness is dependent upon the inspectorate having sufficient expertise to identify hazards and upon their willingness to issue notices when they do. Sanctions for non-compliance should include heavy daily fines.

\section{Licensing}

As many work hazards are created when the enterprise is set up provision should be made for a Safety Licence in respect of new workplaces and work processes. Similarly a licensing or registration system for toxic substances should be provided for.

\section{Written safety policies}

There should be a requirement that each firm has a written safety policy (subject to audit by the OSH Agency) which should set out objectives, identify the main hazards, the managers responsible and the safety organisation within the firm. There should be sufficient accountability to ensure that individual directors and/or managers can be penalised for failure to perform in maintaining safety standards.

The administration and enforcement of the legislation is also crucial to the success of a 
regulatory system. First of all there must be sufficient resources. The low priority and allocation of resources to the Labour Department programme has seriously hampered its effort. An adequate inspection programme is dependent upon having an adequate number of inspectors. The inspectorate must also be appropriately qualified. This does not necessarily mean an academic qualification but the need for a technically competent and skilled inspectorate increases if general duties and performance standards are imposed.

There is also a serious question in my mind about the traditional approach taken by inspectorates to prosecution. "Advise and persuade" has been the approach since last century. I shall briefly address the arguments in favour of this policy:-

1. It is argued that industrial accidents and disease are merely unfortunate by-products of otherwise beneficial activities. As Lang Hancock, the millionaire owner of the infamous Wittenoom Asbestos mine in Western Australia, said,"Some people have to suffer so that the majority can benefit from asbestos."My response is that although the crimes of the powerless rather than the powerful are characterised as "the crime problem" the fact remains that crimes such as contray the crime problen and safety legislation cause enormous human suffering and economic loss. Work hazards should be curbed and vigorous enforcement of safety legislation is one means of doing this.

2. It is asserted that employers accept the need for regulations and are prepared to cooperate voluntarily with inspectors without the need for prosecution. Implicit in this view is that there is an inevitable coincidence between safety and profit. I this view is that there is an inevitable coincidence between safety and profit. I
believe this argument is false. There is often a conflict between safety and profits and in those circumstances there is no economic incentive to voluntarily implement safety measures.

3. It is also argued that criminal law has been tried and failed. In fact inspections have been infrequent, prosecutions rare and penalties derisory. There is good reason to believe that enforcement backed by severe penalties would achieve high standards of compliance.

To sum up therefore, the arguments in favour of the "persuade and advise" philosophy, while convincing in some circumstances (e.g. where profits and safety coincide), are totally unconvincing in others. The fundamental misconception is that most employers want to comply with the law and that only ignorance, carelessness or apathy prevent them from doing so. For a substantial range of hazards this is simply not the case. The harsh reality is that most employers are unlikely to devote scarce resources to a non-productive item such as safety unless they feel that there is some compelling reason to do so. The law could, and should, furnish such "compelling reasons", by establishing minimum standards in such a way that it is both unattractive and unprofitable to fall below them. Use should be made of claims data from the ACC to focus effort on high risk firms and industries. This approach works very effectively in places like British Columbia where the inspectorate is integrated into the Compensation Board.

I should emphasize that I consider that there is also a valuable role for consultative services, education and training programmes, and advice and public information initiatives. There should be no reason for employers to raise ignorance as a reason for failing to meet the required minimum standards.

However, even an inspectorate with substantially increased resources cannot be everywhere at once and there is clearly a need to increase the inspectorate's reach though an effective Health \& Safety Representative System. It is simple logic to enlist the support of those who have the greatest interest in reducing the hazards of work - the potential victims, the workers themselves. They can assist and monitor the performance of the inspectorate.
The Code of Practice negotiated on a tripartite basis through ACOSH provides the opportunity to establish a comprehensive workplace organisation directed exclusively at the prevention of accidents and disease. Experience in other countries (including Sweden the U.K. and Australia), has shown that workers make an effective contribution workplace matters only when they are organised and express themselves collectively Unions provide an organisational structure as well as the back-up and resources that enable workers to reach and promote decions enable that the network of Health \& Safty that the network of Health \& Safety Representatives should mesh into this existing tructure for the provision of resources and basic training.

There has been a very disappointing response to the Code. A recent survey has indicated that only 1.5 percent of employers adopted the complete Code with 10.7 percent adopting it in some modified form, and there is also evidence attempted to avoid any Union involvement. It is clearly necesto the that the Health \& Safety Representative System is fully im to ensure encouraging that the Minister fof encouraging that the Minister of Labour has confirmed publicly on various occasions that
the Government intends to do that.

\section{The legislation}

To conclude I shall outline the principles and objectives which I think should be brought together in the new legislation. The New Act should

* Have a strong objects clause stating the ideal we should be working to achieve. The Norwegian Act provides an example:

To ensure a working environment that provides workers with complete safety against physical and mental hazards and with a standard of technical protection, occupational hygiene and welfare corresponding at all times for the technological and social progress of society.

Provide for the establishment of a tripartite commission which develops health and safety standards and regulations. Its work would be resourced by a research and raining facility or Institute and enforced through an model is specifically provided for in the ACOSH Discussion Paper.

* $\quad$ Establish (in close co-operation with the ACC) a mixed system of experience-ratin and penalty-rating so that the investment of employers in safety is reflected in and penalty-rating so
reduced ACC levies.

* Ensure the continuation of an improved system of enforcement of the standards established by the Commission through a well resourced and well trained Inspectorate who would have the power to impose severe penalties and require compliance.

* Establish a system of licensing new work places, processes, and toxic substances.

* Make mandatory the present Code of Practice for Health and Safety Representatives and Committees.

* $\quad$ Provide resources to ensure that Health \& Safety Representatives are adequately trained and supported through Trade Union Health and Safety Centres and themselves. 
* $\quad$ Provide additional resources to provide specialist training for health professionals involved in occupational health and safety. Occupational health has been the Cinderella of the New Zealand health scene for too long.

* Ensure the continuation of the present rate of health \& safety legislation and regulations pending their review and consolidation by the new Commission.

Finally I would like to acknowledge the extent of agreement on policy matters there has been between the employer and union representatives on ACOSH. I think we all (and I include those who take the trouble to attend a seminar such as this) agree that the mere enactment of new legislation will not in itself solve the problem of workplace hazards, as the history of factory legislation clearly demonstrates. However, if enacted as proposed by ACOSH, I believe it will provide a sound basis for a strong tripartite effort at all levels.

\section{References}

Advisory council for occupational safety \& health (1988) Occupational safety \& health reform: a public discussion paper Wellington.

Ashford, N A (1976) Crisis in the workplace Report to the Ford Foundation:114-115.

Department of Labour (1987) Annual Report.

Glass, W I (1987) In the small work sites New Zealand nursing journal April:17.

Henriques, U (1979) Before the welfare state: social administration in early industrial Britain London, Longman.

International Labour Office (1988) Yearbook of labour statistics Geneva.

Lewis-Beck, M S and Alford, J R (1980) Can government regulate safety? The coal mine example American political science review 74(3):745.

Nichols and Armstrong (1976) Safety or profit Falling Wall Press.

Powell, P and Ors (1971) 2000 accidents National Institute of Psychology, London.

Weiler, P C (1983) Protecting the worker from disability: challenges for the eighties Ontario, Canada, State Government Printing Office. 